\title{
Does Community Context Have an Important Impact on Divorce Risk? A Fixed-Effects Study of Twenty Norwegian First-Marriage Cohorts
}

\section{Le contexte communautaire a-t-il un impact important sur le risque de divorcer? Etude de vingt cohortes norvégiennes de premiers mariages à l'aide de modèles à effets fixes}

\section{Torkild Hovde Lyngstad}

Received: 6 October 2009/Accepted: 12 November 2010/Published online: 4 January 2011 (C) The Author(s) 2010. This article is published with open access at Springerlink.com

\begin{abstract}
The decision to divorce may be affected by the characteristics of the local community. Community characteristics may be barriers to divorce, or they may increase the attractiveness of divorcing (e.g., access to a good remarriage market), but our knowledge of such influences is sparse. This study examines two such community-level factors: socio-economic conditions and the local marriage market. In this study, discrete-time hazard models with community-level fixed effects are estimated using register-based data on Norwegian first marriages during the period from 1980 to 1999 , with longitudinal information on both the community and couple levels $(N=283,493)$. The results show that there are important community-level influences on couples' divorce risk, but these change dramatically when fixed effects are introduced.
\end{abstract}

Keywords Divorce - Community - Context · Fixed effects · Hazard .

Multilevel · Registers

Résumé La décision de divorcer peut être influencée par les caractéristiques communautaires locales. Ces dernières peuvent constituer soit des freins à la décision de divorcer, soit augmenter son attractivité (du fait par exemple d'un marché matrimonial étendu), mais nos connaissances quant à ces influences restent partielles. Cette étude s'intéresse à deux facteurs au niveau communautaire : les conditions socio-économiques et le marché matrimonial local. Des modèles de

\footnotetext{
T. H. Lyngstad ( $₫)$

Department of Sociology and Human Geography, University of Oslo, PO Box 1096 Blindern, 0317 Oslo, Norway

e-mail: t.h.lyngstad@sosgeo.uio.no
} 
risque à temps discret avec effets fixes pour les variables communautaires, sont estimés à partir de registres relatifs aux premiers mariages en Norvège pour la période allant de 1980 à 1999, et d'informations longitudinales tant pour la communauté que pour le couple $(N=283.493)$. Les résultats montrent que les caractéristiques communautaires ont une influence importante sur la probabilité de divorcer, mais la prise en compte des effets fixes modifie considérablement ces résultats.

Mots-clés Divorce - Communauté - Multi-niveaux · Effets fixes · Risque · Contexte $\cdot$ Registre

\section{Introduction}

The factors that contribute to the outcomes of marriages are subject to continuous scrutiny by social scientists. A couple's risk of divorce is influenced by various characteristics of both spouses and their marriage, and large parts of this literature discuss the role of spouses' traits, circumstances, and intra-household processes (White 1990; Lyngstad and Jalovaara 2010). The focus of this study is the effect of the community context on divorce rates, while at the same time considering the spouses' backgrounds, economic situation, and other characteristics. It is conceivable that the likelihood of divorce is affected by characteristics of the community, for example, through local differences in community wealth or the strength of social norms. In fact, most theoretical arguments invoke characteristics of the local community as determinants of divorce. Our knowledge of such factors, however, is very sparse. Community effects have been found for a wide range of demographic phenomena, such as marriage formation (White 1990; Lichter et al. 1991; Lloyd and South 1996; South and Crowder 1999), fertility (Sucoff and Upchurch 1998; Kravdal 2002; Kulu et al. 2007), and mortality (Pickett and Pearl 2001). However, only a handful of contributions have touched upon the potential importance of the community context for marital dissolution patterns (Udry 1983; South and Lloyd 1995; South 2001; South et al. 2001). In addition, these few divorce studies have been based on data sets that are quite small, and many cover limited age ranges or marital durations and include few community variables at the same time. More knowledge about the ways that communities affect their inhabitants' marital outcomes may be useful, not least because this knowledge might help policymakers address the potentially negative consequences of divorce for adults and children (Amato 1993, 2000).

In this article, I provide a broad analysis of the potential impact of community characteristics on divorce risk. I review and clarify theoretical arguments on the effect of community characteristics on divorce risk and empirically assess the effects of several characteristics of the local community, including the local economic conditions and the local marriage market, while controlling for relevant couple-level characteristics. Discrete-time hazard models are estimated using a very rich registerbased data set that covers all first marriages in Norway from 1980 to 1999, linked with annual measurements of characteristics of all Norwegian municipalities over the 
period from 1980 to 2002. With such detailed data on both couples and their communities, it is possible to include fixed effects at the community level that control for time-invariant, unobserved community factors. This control is potentially very important but has not been included in earlier studies.

\section{Possible Pathways from Contextual Factors to Couples' Divorce Risk}

There may be multiple pathways from a couple's community to their divorce risk. Building on previous research in this area, I review several arguments about the features of the community that may be important for divorce risk. All of the arguments are presented within the larger framework of analytical sociology (Hedström 2005), where the various links between a community feature and a couple's divorce risk are denoted causal mechanisms.

These causal mechanisms are "microtheories" that represent a specific type of community influence on couples' divorce decisions. There may be multiple mechanisms linking each community-level variable to divorce, which may work in opposite directions. Unless there is strong reason to believe that one mechanism is much more important than another, it is not possible to make a strong claim about the expected total effect of a single community variable.

\subsection{Marriage Market Balance and Population Density}

The likelihood of divorce may be dependent on how easy it is (or is perceived to be) for potential divorcees to find a new partner. The macrostructural opportunity theory of marital dissolution proposed by South et al. (2001) says that a person's decision to leave the current partner is contingent on his or her chance of meeting a new partner. Therefore, this decision is affected by characteristics such as the degree of sex segregation in the workplace and the sex composition of the population (South et al. 2001). This literature suggests that the relative supply of spousal alternatives affects the risk of marital dissolution. If, for example, a husband has more options for a potential remarriage than his wife does, he would be more inclined to divorce than she would (Udry 1983; South et al. 2001). If one of the spouses faces a marriage market with numerous alternative partners or simply perceives the likelihood of remarriage with a new partner as good, the couple's risk of divorce increases. A frequently cited contribution to the importance of this relative-supply mechanism for divorce is the study by South and Lloyd (1995). They estimated the effect of local spousal alternatives (measured by the ratio of single men to single women) on the divorce rate, net of individual-level and some macro-level variables. Their results showed that couples living in areas with sex imbalances had a higher propensity to divorce. However, this line of reasoning might overstate the disruptive effect of an abundant supply of alternative partners for one of the spouses. South and Lloyd write, "It only takes one tempted, motivated partner to dissolve a marriage," but their arguments do not explicitly clarify why relative partner supply leads to a stronger temptation to divorce only for the spouse who experiences a relatively good market. There could also be an opposite effect that makes the other 
spouse more willing to make concessions to keep the marriage in good condition (or, in economic theory terms, allowing the partner to get a larger share of the utility from marriage). This opposite effect can be called the commitment mechanism. When measured through sex ratios, a good market for one spouse implies a bad market for the other spouse, and the total net effect is indeterminate.

Moreover, it is not a simple matter to numerically measure the spouses' relative supply of potential partners. For example, due to data limitations, a fixed age group is often used to calculate the sex ratio. In my analysis, I use a slightly more refined and time-varying definition than that used in earlier studies. Of course, in the age of Internet dating services and other means of communication between potential partners, the age-specific sex composition and population density of the local area are not the only possible indicators of the availability of alternative partners and the costs of finding new partners. Even so, for the most part, social interaction takes place in communities, and most people meet their partner in settings such as workplaces and schools (Kalmijn and Flap 2001; Lampard 2007). Given the indeterminate nature of the relationship between marriage market conditions and divorce risk suggested above, I do not offer a specific hypothesis. Nevertheless, I include a slightly refined measure of spousal alternatives in the model.

The sheer volume of the local marriage market might also play a role in divorce risk. There might be differences among communities regarding how easy it is to locate a sufficiently good match, which is equivalent to the search costs of finding a (new) partner. If the search costs are relatively low in the community, unhappy spouses should be relatively more willing to divorce and undertake a search for a new partner. One of the findings that has been replicated numerous times in the literature is that urbanites run a higher risk of divorce than couples living in rural areas (Shelton 1987; Bracher et al. 1993; Kalmijn and Poortman 2006). The anonymity offered by an urban environment might, for example, reduce the perceived risk of initiating extramarital affairs or ease any stigma associated with being divorced (Kalmijn and Uunk 2007; Lyngstad 2006). Another reason that population density should matter is that the shorter distances and the superior communications of urban centers reduce the costs associated with finding a new partner, and the pool of persons in the local area among which a (future) divorcee could search for a new partner is larger. In this context, one might argue that divorce risk increases with the population density of the community. However, the previously reported effects of place of residence were obtained without regard for other community-related factors and focus exclusively on regional or urban/rural differentials in divorce risk. It might be that such effects are seriously confounded by other community-level variables.

\subsection{Economic Conditions in the Community}

The socio-economic structure of the community might also affect divorce rates in several ways. The common denominator of these ideas is that relative levels of wealth and prosperity in communities produce non-economic social influences on spouses' decision making, regardless of the spouses' own economic situation. Mechanisms linking economic conditions and divorce risk may work in either direction. 
Theoretical discussions of the potential impact of disadvantaged neighborhoods on family structure have suggested that divorce rates may be higher in such areas (South 2001; South and Crowder 1999). Populations in poor areas often display high rates of problem behavior (such as drug abuse), a general attitude of pessimism, and lack of investment in the infrastructure. In studies of the effect of community on health and crime outcomes, people who live in economically deprived areas have more negative outcomes than others, all else being equal. The classic "Marienthal" study of the community effects of unemployment showed that high unemployment has negative consequences not only for unemployed individuals but is also linked to a retreat from public life, a general attitude of fatalism, lower political interest, and the dissolution of social networks (Jahoda et al. 1933). These phenomena, which could be conceptualized as either lower collective efficacy (Sampson et al. 1997) or a depreciation of the social capital in the community (Astone et al. 1999), affect not only the unemployed but also the larger community, and thus also married couples in an average or good financial position. One would therefore expect that economic disadvantage leads to higher divorce rates, when the spouses' own financial situation is controlled. A study in the United States found that an effect of neighborhood socio-economic disadvantage could be fully explained by the spouses' incomes (South 2001). However, the data provided few opportunities to control for other community-level factors.

Sociological reference group theory and social comparison theory predict that if a community is relatively affluent, residents' standards of consumption will be higher and spouses' aspirations for consumption will be higher (Festinger 1954; Hyman 1960). It has been shown empirically that individual income aspirations increase with average income in the community, regardless of the individuals' income (Stutzer 2004), and that perceived well-being declines as one's neighbors increase their earnings (Luttmer 2005). These community effects on individuals' preferences and beliefs may lead to community differences in spouses' evaluations of the economic consequences of divorce. Relatively high economic costs of divorce could make potential divorcees think twice about leaving their partners because, should the relationship end, at least one of the spouses must find new housing, and neither will benefit from the economies of scale of a joint household. Even when a couple's actual economic situation is well controlled for, the change in consumption as a result of a divorce might be perceived differently by people living in affluent communities and people living in poorer communities, thereby changing the attractiveness of singlehood or remarriage relative to remaining married to the current partner. If the economic consequences are perceived as severer in affluent communities, divorce rates might rise when economic conditions in the community deteriorate. Another mechanism, working in the opposite direction, is that good economic conditions may induce a general sense of economic optimism about the future, which leads people to underestimate the economic changes associated with divorcing.

\subsection{Aggregate Education}

The average level of education in the community can also affect the divorce rate. The possible routes from a community's aggregate education to a couple's divorce 
risk may be through the normative climate or through social imitation channels. Aggregate education may also reflect the residual influence of economic conditions after controlling for observed economic variables at both macro- and micro-levels.

An increasing average level of education and widening distribution of education in society may be an engine driving society toward more emphasis on personal freedom and self-realization (Inglehart 1990, 1997). Following this line of reasoning, a large proportion of people with higher education in the community might be indicative of a normative climate that is more liberal than in communities with a lower proportion of such persons. Highly educated persons, at least in the past, have tended to hold more accepting attitudes toward behaviors such as divorce and homosexuality (Listhaug 1998). This result would suggest that communities with high average education levels have higher divorce rates than other communities.

Another possible mechanism linking aggregate education and the divorce rate, although in the opposite direction, is a variant of social imitation. It is very well documented, at least in Scandinavia, that highly educated couples have much lower divorce rates than other couples regardless of labor force attachment, family structure, and a host of other factors (Jalovaara 2003; Lyngstad 2004). Regardless of why these couples enjoy lower divorce rates, their behavior might set a standard for the community, and they may serve as role models. A social imitation mechanism may therefore produce lower divorce rates in communities with a high proportion of highly educated people.

A community with a high level of knowledge and skills might be a better place to live regardless of individuals' investments in education. This outcome might occur, for example, through economic factors such as higher numbers of available, wellpaying jobs, higher rates of entrepreneurship, or a stronger feeling of economic security, giving people a more optimistic economic outlook than in communities with lower human capital. According to this perspective, a large number of people with extended education in a community should be negatively correlated with divorce risk. Once the economic circumstances in the community are perfectly controlled, however, this economic component of aggregate education should not be relevant. However, in most empirical analyses, the controls for economic conditions are not perfect, and the effects of aggregate education might reflect these components. An accurate prediction of how aggregate education affects divorce rates is not possible from these arguments, but any result would indicate where to look for the actual mechanism in subsequent analyses.

\section{Data and Method}

\subsection{Data}

The data for this study were obtained from various Norwegian administrative registers. In Norway, a system of universal identity numbers uniquely identifies each individual who has ever officially resided in the country. In administrative records, this number is used to identify each individual and facilitates the linking of data from 
different registers. There are also links between every child born and its parents. To construct the data set used here, data on the population of marriages were generated from time series of individuals' marital status. This stage identified the couples, the outcomes of their marriages, and other basic demographic information. Then data from registers with other longitudinal information on the spouses were linked to the couple data set. Finally, data on the community context were linked to the couple data. It is important to understand that the couples do not self-report anything, but rather that the data are collected from other government institutions. For example, data on completed education are reported directly from the educational institutions to the government, and data on individuals' incomes are reported through annual tax returns. These administrative register data allow us to avoid the problems with high panel attrition and non-response rates that often plague longitudinal sample surveys. For more information on administrative register data sources, their quality, accuracy, and uses, see, for example, Røed and Raaum (2003).

A drawback of the register data set, apart from not providing subjective evaluation variables, is that only marital unions are included. Cohabitation increased in popularity in Norway over the study period. In 1980, cohabitation was a marginal phenomenon among all but the youngest age group, but in 2000, between a quarter and a third of all individuals in their 30s were cohabiting (Statistics Norway 2010). It would be preferable to include informal unions in the analysis and thus generalize the findings to the whole population of couples. However, because a majority of Norwegian children live with married parents (Statistics Norway 2010) and a majority of Norwegians expect to marry at some point in their lives (Lyngstad and Noack 2005), it seems worthwhile to study only married couples from both a scientific and policy perspective. It is possible, and even likely, that the prevalence of cohabitation increased over the study period at different rates in different communities. The prevalence of cohabitation is likely to influence people's marriage decisions and, consequently, which couples are selected into marriage. It is unclear how these selection processes could translate into different community effects on divorce risk or bias the estimated parameters.

The final data set included 283,493 Norwegian first marriages contracted from 1980 to 1999 . The unit of analysis was the couple, and all couples were followed until either divorce or censoring occurred. The observation period ended in 2002. Time series of educational attainment and enrollment, annual labor market earnings, and municipality of residence are available for both spouses during the whole period (although there is a gap for educational attainment and enrollment for the years 1983 and 1984). In addition, there are fertility histories for each spouse, with information on every child born to the spouse (including children born outside of the current marriage). Municipality of residence defines the couple's local community. As the data include an annual measurement of spouses' municipality of residence, the couples could be followed even if they move between municipalities.

The community-level variables are taken partly from the Norwegian Social Science Data Services' Municipality Database and partly aggregated from registerbased, individual-level data files. The aggregate community variables were generated based on population-wide registers, not using the couple-level data set. I have annual measurements of all community-level variables. 


\subsection{Statistical Model}

Discrete-time hazard models are estimated (Allison 1995). With this method, each marriage record in the data set is split up into a number of observations of marriage years. A couple observed for 10 years would thus contribute ten marriage years to the data set. If a divorce takes place in year $t$, then the dependent variable is set to one for the corresponding marriage year; otherwise, it is zero. After emigration or a spousal death, the marriage observation was censored. Time units other than calendar years could be used, but an annual step was reasonable and practical in this analysis. Only the marriage years that have valid information on municipality of residence are included in the analysis. The 3,266,225 marriage years were spread out over 434 communities and entered into a logistic regression model for the analysis.

When data are organized in hierarchical structures, multilevel methods should be employed (Goldstein 2003). There are several possible ways of accommodating this hierarchical data structure. In a multilevel study of divorce, the researcher is typically faced with two separate problems. One is that couples are nested in communities, which deflates the standard errors for community-level parameters and may yield wrong hypothesis tests. This serious problem is often remedied by including in the model a random effect term with identical draws for each community in the model. This approach is considered by some to be the main feature of a "multilevel model," although any study that involves a hierarchical data structure may be referred to by this name.

Even when standard errors are appropriately estimated, another problem remains: unobserved factors may confound the relationship between the community characteristics, on the one hand, and a couple's decision making, on the other hand. There are likely to be differences in divorce risk between communities along some unmeasured variables. If these are associated with the observed community factors, these differences will confound the relationship between the observed community variables and couples' divorce risk. Parameters of effects of community variables may thus be biased. All previous studies are to my knowledge subject to this important criticism.

In the final model, I take the very powerful fixed-effects approach where unobservable variables at the level of the community are included as a large set of dummy variables. Each dummy variable represents a municipality and captures the time-constant features of this municipality and its influences on the divorce rate. The features that are constant over time may include values and norms, aspects such as the built environment or features of dominant industries. A municipality dominated by a military base might be different from a municipality that is dominated by industrial plants but is otherwise similar. The fixed-effects approach has the advantage over random effect models that the unobserved factors captured by the fixed-effect dummies can be correlated with the observed community factors. However, it requires the observed community variables to be time-varying. Otherwise, there will be perfect collinearity between the constant-over-time community variables and community dummy variables. Studies using similar register data have employed this method to estimate parameters for the effect of community variables on other demographic rates 
(Kravdal 2007, 2008; Rindfuss et al. 2007). Mathematically, the model that was estimated can be written as

$$
\ln \frac{P\left(Y_{i j t}=1\right)}{1-P\left(Y_{i j t}=1\right)}=\alpha_{t}+\beta X_{i j}+\delta Z_{i j t}+\lambda M_{j t}+\eta_{j},
$$

where $Y_{i j t}$ represents the outcome dummy variable, $\alpha_{t}$ are the duration baseline parameters, $\beta$ and $\delta$ are parameters for time-constant and time-varying couple-level variables, $\lambda$ are parameters for community-level variables, and $\eta_{j}$ represents the community fixed effects. The models without fixed effects are identical, with the exception that the last term, $\eta_{j}$, is not included. Note that the fixed effects do not represent the mean of the community variables, but rather the contribution of unmeasured and omitted community variables on divorce risk.

Why is a random effect at the community level not included in addition to the community fixed-effects controls for the model to provide better estimates of the standard errors of community-effect parameters? The main reason for this is that computational problems arise when estimating such models with very large multilevel data sets (typically, register-based data sets). In this case, estimation failed with SAS PROC NLMIXED, aML, and Stata. The technical reason is that the likelihood value "underflows" (becomes too small for the computer to represent it) for large clusters of sub-observations, such as major cities. Other scholars using similar data and similar methods have experienced the same problems (e.g., Kravdal 2007). If the estimation algorithm for a model with a random effect were to successfully converge, standard errors would likely be markedly bigger.

When a couple moves from one municipality to another, in the years following the move, their value on the community variables will change to those measured for their destination. This result means that their risk of divorce in the years subsequent to the move will be affected by the community factors defined by the characteristics of the new community.

\subsection{Individual- and Couple-Level Variables}

All variables pertaining to the couple are measured for both spouses where relevant. Marriage duration, marriage cohort, the couple's annual labor market earnings, spouses' educational attainment, spouses' educational activity, their parity and the age of their youngest child, and spouses' family structure and ages at marriage are all measured by categorical variables. Note that separate parameters are estimated for a husband's and wife's characteristics, unless the variable captures a characteristic of the marriage or household (which, by definition, is the same for both spouses). The spouses' annual labor market earnings are measured in inflation-adjusted Norwegian Kroner with two five-category variables. Capital incomes or public transfers are not included in this earnings measure. A different categorization is used for men and women because of women's generally lower labor market earnings (a product of part-time work or spells of unpaid maternity leave). Educational attainment is grouped in four levels: primary, secondary, college level, and postgraduate level. As no effect of educational homogamy has been found in other Scandinavian studies 
(Jalovaara 2003; Lyngstad 2004), no interaction or combination effect is included for the spouses' educational attainments. The variables are time-varying and updated annually (with the exception of 1983 and 1984). Educational activity is measured by a time-varying dummy variable. Educational activity might lead to low labor market earnings, but it may also provide access to a large pool of potential partners. For some spouses, it might also represent a preparation for single life in the case of divorce; an investment in more human capital can alleviate economic problems after divorce. Parity and age of youngest child is grouped into ten categories, with childless as the baseline. For parities one, two, and three or more, there are three categories of ages: child is aged less than 1 year, from 1 to 6 years, or 7 years or older. The variables measuring spouses' family structures are categorized as follows: intact family, non-intact family due to parents' death, and non-intact family due to divorce. Indeterminate cases constitute a separate category. These variables are measured at the time of the spouses' marriage. In addition to these control variables, period effects are included as a set of 1-year dummy variables (not shown in tables).

\subsection{Community-Level Variables}

All community-level variables are computed separately for each municipality and each year unless otherwise noted (i.e., they are annual community-specific time series). Population density is included as a continuous variable. Clearly, using only population density is a crude measure for capturing the urban/rural dimensions because some communities might have large unsettled areas driving the population density down, while the population is actually concentrated in a few larger, high-density settlements. However, any classification would potentially contain equally important sources of bias. With the chosen definition, this study benefits from an essentially time-varying variable that can be included in fixedeffect models.

Marriage market conditions are measured by the deviation from the sex ratio of the local population in two specific age ranges. It is likely that as individuals' age, their preferred age for an alternative partner also increases. I include only persons that are of about the same age as the spouses themselves, taking into account that the husband is usually slightly older than the wife. The husband's alternatives are defined as women in somewhat younger age range to women slightly older than he is ( -10 to 5 years). The wife's alternatives are defined as men in a slightly younger age range to men somewhat older than she is ( -5 to 10 years). Although all assumptions about age preferences are arbitrary to some extent, ignoring age norms and preferences for partners would be less effective. South and Lloyd (1995) required persons to be single to present a suitable alternative. I assume that in a highly dynamic family system with high levels of union disruption, even married individuals may be considered alternative partners. I will thus use the sex ratio of all individuals, regardless of marital status, in the two age ranges as the measure of spousal alternatives. The partner supply might affect men and women differently, as do several other characteristics (Kalmijn and Poortman 2006). To accommodate 
different effects of partner supply for husbands and wives, in accordance with South and Lloyd (1995), a curvilinear relationship between spousal alternatives and divorce risk is allowed, using a quadratic term. This is the only variable receiving this treatment because there are no theoretical reasons to expect non-linearities in the other community effects. Experiments were conducted to insure that no important empirical pattern was undiscovered.

Average labor market earnings in each municipality are measured in thousands of inflation-adjusted Norwegian Kroner, with 1980 as the baseline year. As only labor market earnings of persons aged 16-66 are included, pensions and capital income do not contribute to the average. The male unemployment rate is defined as the proportion of registered unemployed men to the number of men aged 16-67 years in the municipality. Aggregate education is defined as the proportion of persons with some tertiary education in a given calendar year. All individuals in the municipality who are older than 19 years of age are included in the denominator. Table 1 lists descriptive statistics for all community-level variables calculated on the basis of all community-year observations. The various community-level variables are correlated, with absolute estimates ranging from 0.03 to 0.8 (mean income and proportion with higher education). This is further evidence for including multiple measures of community context in the same model.

\section{Results}

I estimate two discrete-time hazard models. Both models include all couple-level variables, duration of marriage, and period effects. First, I estimate a model with community variables included but where unobserved community factors are ignored. In the second model, I introduce community fixed effects, which control for unobserved variation between communities. In the following sections, I comment on the results for each domain of community influences across models. Table 2 shows the unstandardized parameter estimates, associated standard errors,

Table 1 Descriptive statistics for community-level variables calculated on the basis of all marriage-year observations

\begin{tabular}{lrr}
\hline Community variables & \multicolumn{1}{c}{$M$} & \multicolumn{1}{c}{ SD } \\
\hline Population density (persons $/ \mathrm{km}^{2}$ ) & 267.26 & 370.58 \\
Alternative sex ratio (number of men to 100 women) & 102.90 & 8.37 \\
Proportion with higher education (\%) & 20.18 & 8.07 \\
Mean income (1000 Norwegian Kroner) & 66.70 & 12.95 \\
Unemployment rate (\%) & 3.04 & 1.51 \\
\hline
\end{tabular}

Source: Calculations on register data on Norwegian first marriages 1980-1999 
Table 2 Parameter estimates for community-level variables included in discrete-time hazard models of divorce

\begin{tabular}{|c|c|c|c|c|c|c|c|c|}
\hline \multirow[t]{2}{*}{ Community variable } & \multicolumn{4}{|c|}{ Model 1: model without fixed effects } & \multicolumn{4}{|c|}{ Model 2: model with fixed effects } \\
\hline & Beta & SE & $p$-value & $\begin{array}{l}\text { Effect } \\
\text { measure }^{a}\end{array}$ & Beta & $\mathrm{SE}$ & $p$-value & $\begin{array}{l}\text { Effect } \\
\text { measure }^{a}\end{array}$ \\
\hline Population density & 0.00003 & 0.00002 & 0.062 & 1.01 & -0.0007 & 0.0004 & 0.060 & 0.77 \\
\hline $\begin{array}{l}\text { Sex ratio of spousal } \\
\text { alternatives }\end{array}$ & 0.0988 & 0.0081 & $<0.001$ & 0.92 & 0.0973 & 0.0088 & $<0.001$ & 0.92 \\
\hline $\begin{array}{l}\text { Sex ratio of spousal } \\
\text { alternatives squared }\end{array}$ & -0.0005 & 0.00004 & $<0.001$ & & -0.0005 & 0.00001 & $<0.001$ & \\
\hline $\begin{array}{l}\text { Proportion with } \\
\text { higher education }\end{array}$ & 0.0081 & 0.0013 & $<0.001$ & 1.07 & -0.0335 & 0.0063 & $<0.001$ & 0.76 \\
\hline Mean earnings & 0.0047 & 0.0010 & $<0.001$ & 1.06 & 0.0044 & 0.0029 & 0.216 & 1.06 \\
\hline Unemployment rate & 0.0395 & 0.0049 & $<0.001$ & 1.06 & -0.0088 & 0.0072 & 0.342 & 0.99 \\
\hline
\end{tabular}

Source: Calculations on register data on Norwegian first marriages 1980-1999

a These columns report the relative change in odds of divorce for a change equal to one standard deviation in the community variable. For the sex ratio variable the relative change in odds is calculated from the mean sex ratio

and semi-standardized coefficients from both estimation rounds. The semistandardized coefficients were calculated as the change in odds for one standard deviation change in the community variable. Complete results from the two regression models are reported in Table 3 (Appendix).

\subsection{Results from the Model without Fixed Effects}

In Model 1, all of the community characteristics are included, and one can assess the importance of one community factor independently of the other observed community factors included in the model. Unobserved factors at the community level are ignored. Only one parameter estimate for community variables is not significantly different from zero. Population density does not have a measurable impact on the risk of divorce in this model. The parameter estimates for the remaining variables are all significantly different from zero. A high rate of male unemployment, a high level of mean earnings, and a high proportion of highly educated people in the community are all associated with a higher divorce risk for couples living under such circumstances. These results do lend some support to the idea that community economic conditions impact couples' divorce risk. However, implications for theory are not clear as the two relevant variables, mean earnings and male unemployment, pull in opposite directions.

Contrary to the findings of earlier studies, an imbalanced remarriage market does not markedly increase divorce risk. According to this model, large deviations in the sex ratio are associated with lower risks of divorce, particularly so if the remarriage market favors men (i.e., if there are fewer men per woman in the appropriate age groups). 


\subsection{Results from Model with Community Fixed Effects}

Model 2 includes community-level fixed effects and provides an accurate control for unobserved time-constant factors at the community level. This control is important because the parameters for the community variables in Model 1 may be severely confounded.

Many parameter estimates change markedly when the unobserved factors at the community level are taken into account. One example of this type of change is the parameter estimate for aggregate education, which again emerges as a significant predictor of divorce. However, in this model, the parameter estimate is turned around. There seems to be an important divorce-reducing effect in communities with a high proportion of highly educated people when other unobserved characteristics of the community are held constant. This finding implies that some time-constant unobserved factor is positively correlated with divorce and negatively correlated with aggregate education, and that inclusion of the fixed-effects controls for this factor. It is not atypical to see such reversals in studies using community fixed effects. A similar case is reported in Rindfuss et al. (2007). With the data at hand, it is difficult to gain more insight into the nature of this unobserved factor, but it is clear that mere associations of aggregate levels of education with divorce should not be understood to represent any causal mechanism, even when other characteristics of the community are controlled.

Population density is still not a significant predictor of divorce when unobserved factors are included, suggesting that the frequently observed higher risk of divorce for urbanites cannot be due to a higher population density in cities (for example, because of lower search costs). It is clear that community economic conditions are not particularly important predictors of marital dissolution. The unemployment and earnings variables become insignificant with the introduction of fixed effects.

The only result that is stable across models is the effect of the sex ratio of alternative partners. These parameters are statistically significant, go in the same direction, and are of approximately the same magnitude as those obtained from Model 1. The total impact of a slightly imbalanced marriage market is small, but with extreme sex ratios, the relative odds of divorce decline rapidly. The curvilinear relationship reaches its maximum at sex ratios of around 97 men per 100 womenin effect, at near parity between the sexes.

When one compares the magnitude of the parameter estimates for community effects from Model 2 and estimates for typical couple-level variables, it can be tempting to conclude that community effects are unimportant for divorce decision making. Such temptations should be resisted. For example, an increase of one standard deviation in the proportion of people with higher education is associated with a reduction in the odds of divorce of around $15 \%$, which is comparable in magnitude to commonly found effects of individual or couple-level determinants.

\subsection{Fixed-Effects Estimates (Not Shown in Tables)}

Ranked by size, the fixed-effects estimates obtained from Model 2 show a familiar pattern: the southwestern region generally displays the lowest divorce risk, net of all 
included community factors. Rural areas in the southeast and the central regions, however, also have low divorce rates. Fixed effects for urban communities are mostly positive, indicating higher risks of divorce. Therefore, there seems to be some time-constant factor, unrelated to population density, which produces the urban/rural difference demonstrated quite often in the literature. One possible explanation is that urban areas are culturally liberal environments where acceptance of divorce is high, and this phenomenon is not captured by any of the observed community-level variables or by the controls for unobserved time-constant factors considered in the fixed-effect models.

\subsection{Results for Control Variables}

All of the couple level, variables included in the models conform to recently published results on divorce determinants in the Nordic countries (Jalovaara 2003; Lyngstad 2006). I find negative effects for both spouses' ages at marriage, educational attainment, and the number and age of children. Parents' divorce, educational activity, and wife's earnings are positively related to divorce risk. The couple-level factors are also remarkably stable across models, both with and without all community-level variables. The duration pattern reaches its peak around the sixth year of marriage and subsequently declines, while there is a monotonic increase in divorce risk over the period as a whole.

\section{Discussion and Conclusion}

In summary, this study has shown that there is substantial variation in divorce risk between different community contexts, but some theoretically expected community effects do not appear. In addition, it is clear that unobserved community factors are important and are correlated with the observed community variables. How can these results be understood in light of the theoretical arguments and predictions?

First, many previous studies found urban areas to have the highest divorce rates. Many of these studies did not have access to a large set of other community-level variables, nor could they control for many couple-level characteristics. A more critical view on this assertion is now warranted. From the results obtained in this study, it seems likely that the idea that urban areas have higher divorce rates is too simplistic. Measures of population density or urban/rural residence might pick up various other community influences when included in models of divorce. When included as the only community factor, the parameter for population density shows a positive effect (this result is not shown in the tables). When the other observed and unobserved community factors are included, as in models 1 and 2, the effect is not measurably different from zero. The implication is that the higher divorce risk of urbanites cannot be explained by the higher population density and lower search costs in urban environments. Urbanites have a higher risk, but it is not because they live in densely populated areas but because of other features of their environment.

Second, a solid finding from the statistical analysis is that the availability of potential partners, when defined as an age-staggered sex ratio, is not associated with 
an increase in the divorce rate, but with a small decline. As argued above, there are multiple mechanisms linking spousal alternatives to divorce, rendering the effect of this variable theoretically indeterminate. The mechanism suggested by previous studies was that spouses with many options would be tempted to leave their current marriage, driving dissolution rates up. However, this temptation mechanism goes hand in hand with an opposite mechanism based on commitment. When the sex imbalance is very large, it should be obvious to both spouses which one of them has good or poor prospects for remarriage. In such situations, a couple could perhaps reorient itself away from possible alternative partners in an attempt to neutralize the outside "threat." Of course, it is also possible that both or neither of the two suggested mechanisms is at work in the divorce process. In that case, a null effect or estimates close to a null effect could be observed. An alternative specification with dummy variables was also used, but it yielded results that were similar to those reported here.

Regardless of its exact interpretation, the result shows that, at least in contexts where there are large and probably easily identifiable imbalances, the temptation mechanism does not dominate couples' behavior. This finding is clearly not consonant with what has been called the "macrostructural-opportunity theory of marital dissolution" (South 2001), which argues that the likelihood of divorcing is affected by the supply of alternative partners for remarriage. Either the measure of spousal alternatives used here is insufficient to assess the ratio of actual relevant alternatives, or the idea that the relative supply of alternatives should increase rates of divorce is incorrect or too simplistic. Recent empirical studies of the impact of sex distributions in workplaces find some evidence for the "macro-structural opportunity hypothesis" (McKinnish 2007; Svarer 2007), but this study clearly does not. The reader must be aware, however, that spousal alternatives are notoriously difficult to measure, and no attempt was made in this analysis to measure the spouses' number of actual alternatives using social network data or similar sources. However, these results show that results from previous studies linking spousal alternatives in the local community (as defined by geographical area) to divorce risk should be interpreted with more caution.

Turning to the arguments about economic conditions in the community, a major conclusion is that important aspects of the local economy, although measured crudely by average earnings and unemployment, seem completely unimportant for couples' decisions to divorce, contrary to theoretical predictions. One suggested mechanism linked the relative poverty of a community with a higher divorce risk through a number of possible causal pathways, while others suggested that divorce decisions are affected by spouses' perceptions of the post-divorce standard of living and that these perceptions vary with the economic standing of those in one's environment. With the results from Model 2, it is clear that the link between the economic situation in the community and the divorce risk is either ignorable or that neither of these mechanisms dominates the others and that they together (possibly in concert with yet other mechanisms) produce a null effect. However, these findings must be understood within a wider national context, aspects of which include a generous welfare state system, positive attitudes toward economic egalitarianism, a compressed wage distribution, and extensive legal protection of employees in the 
case of downsizing. These factors contribute to reduce outright poverty and weaken the impact of business cycles on the population's welfare level. Thus, the Norwegian case should be considered a conservative test of these ideas.

The effect of aggregate education level, or the stock of human capital in the community, changes sign when unobserved community factors are controlled for. According to Model 2, an increase in aggregate education leads to a marked decrease in the divorce rate. This dramatic change in parameter estimate must be due to a correlation between aggregate education and some feature of the local community that is constant over time. Assuming that geographical differences in normative structures are fairly stable over time, as has been shown for a number of demographic behaviors by Lesthaeghe and Neels (2002), I suspect that such structures may make up a sizable portion of the unobserved factors. If this suspicion is correct and there is a correlation between aggregate education and the normative climate in the community, we will observe a positive effect of aggregate education in Model 1 that is spurious. Such a correlation may explain the change between models in the effect of aggregate education. In the first model, the estimated effect of aggregate education is the sum of the causal effect of education and a spurious effect due to a correlation between highly educated populations and liberal populations in communities. Once the spurious component is controlled for by way of the fixed effects included in the second model, we observe a parameter estimate of aggregate education that should be closer to the causal effect of education.

The interpretation of the negative effect of aggregate education in Model 2 is not unambiguous. Communities with high average education might have more opportunities for marriage education or counseling. This finding corresponds with the strong negative effects found for the spouses' individual educations (Jalovaara 2003; Lyngstad 2006). One possible explanation for the result for aggregate education is that it emerges due to social imitation. Divorce rates are reduced for couples living in communities with high levels of aggregate education because the spouses' social networks might contain people with more education, and the spouses learn or imitate something that reduces the divorce rate of highly educated people. The nature of this feature, which is imitated or learned through social networks and is relevant for marital dissolution, is unclear. A second possibility is that, even though the economic conditions in the community are controlled, these covariates may not pick up all of the contributions of variation in such conditions. However, because the economic condition measures are unimportant, this explanation seems less likely. A third and final interpretation of the effect of aggregate education is connected to differences in actual marriage market conditions by spouses' education levels. Assuming that people have preferences for partners with education levels similar to their own, a community with many highly educated people (who enjoy relatively low divorce rates) will produce a particularly poor remarriage market that might not be captured by the general sex ratio of spousal alternatives used here.

The total impact of community characteristics is demonstrated to be modest but comparable in magnitude to some well-known predictors of divorce at the couple level. The most serious limitations of this study are that cohabitants are excluded 
and that it does not control for couple-level indicators of unemployment. However, an indicator of unemployment would be strongly associated with having very low labor market earnings, which is included in the model. There are no theoretical arguments for why the community effects should affect cohabiting and married couples differently. The lack of data on cohabiting unions limits the generality of these findings to marital unions.

An important general conclusion that may be drawn from these results is that observed community characteristics will be correlated with unobserved community characteristics variables, and thus, parameter estimates for the former will be biased. It is clear from the results presented in this study that estimates of community effects in divorce rate models are very sensitive to the inclusion of fixed-effects controls for unobserved characteristics of communities. As the fixed-effect controls may summarize a wide range of influences on divorce risk, it is difficult to give a substantive interpretation to the change in coefficients. The changes mean that something unobserved, fairly stable over time, and related to each community is affecting couples' likelihood of divorcing through a set of unspecified mechanisms. For example, this might include (but would not be limited to) deeper socio-cultural mores and value systems as well as features of the built and natural environment. The fact that the results for observed community factors change when fixed effects are included implies that the unobserved factors are associated with the observed variables and that such controls should be included in future studies.

In turn, this general conclusion also implies that the value of studies of community context without controls for unobservable community variables is rather limited, unless the goal of the research effort is merely to provide a description of correlations between contextual variables and demographic behavior rather than to make a claim for a causal relationship between community characteristics and couples' divorce decisions. Further research should explore in more depth the causal mechanisms responsible for the results reported here, such as what mechanism is behind the negative effects on the divorce rate of living among highly educated people and why a high availability of alternative partners seems to reduce divorce risk, contrary to theoretical predictions.

Acknowledgments The author is thankful for financial support from the Research Council of Norway for this project (grant number 159666/730), and for comments on previous drafts from the EJP editor, two anonymous reviewers, Gunnar Andersson, Fredrik Engelstad, Øystein Kravdal, Francesca Michielin, Fernando Riosmena, Wendy Sigle-Rushton, Kenneth Aa. Wiik, and audiences at PAA 2007 annual meeting in New York, the Max Planck Institute for Demographic Research, and the Vienna Institute for Demography. Some of the community-level data were obtained from the Norwegian Social Science Data Services.

Open Access This article is distributed under the terms of the Creative Commons Attribution Noncommercial License which permits any noncommercial use, distribution, and reproduction in any medium, provided the original author(s) and source are credited.

\section{Appendix}

See Table 3. 
Table 3 Complete results from discrete-time hazard regression models of divorce in Norwegian first marriages 1980-2002

\begin{tabular}{|c|c|c|c|c|c|c|c|}
\hline \multirow[t]{2}{*}{ Variable } & \multirow[t]{2}{*}{ Category } & \multicolumn{3}{|c|}{ Model 1: no fixed-effects } & \multicolumn{3}{|c|}{ Model 2: with fixed-effects } \\
\hline & & $B$ & SE $B$ & $p$ & $B$ & SE $B$ & $p$ \\
\hline Intercept & & -9.02 & 0.43 & $<0.001$ & -8.31 & 0.49 & $<0.001$ \\
\hline \multirow[t]{8}{*}{ Duration } & 1 & -4.99 & 0.13 & $<0.001$ & -4.99 & 0.13 & $<0.001$ \\
\hline & 2 & -1.53 & 0.03 & $<0.001$ & -1.53 & 0.03 & $<0.001$ \\
\hline & 3 & -0.44 & 0.02 & $<0.001$ & -0.44 & 0.02 & $<0.001$ \\
\hline & 4 & -0.13 & 0.02 & $<0.001$ & -0.13 & 0.02 & $<0.001$ \\
\hline & $5-7$ & & & & & & \\
\hline & $8-10$ & -0.06 & 0.01 & $<0.001$ & -0.06 & 0.01 & $<0.001$ \\
\hline & $11-14$ & -0.26 & 0.02 & $<0.001$ & -0.25 & 0.02 & $<0.001$ \\
\hline & $15+$ & -0.57 & 0.02 & $<0.001$ & -0.57 & 0.02 & $<0.001$ \\
\hline \multirow{4}{*}{$\begin{array}{l}\text { Husband's age at } \\
\text { marriage }\end{array}$} & Up to 24 & 0.12 & 0.01 & $<0.001$ & 0.13 & 0.01 & $<0.001$ \\
\hline & $25-29$ & & & & & & \\
\hline & $30-34$ & -0.03 & 0.01 & 0.045 & -0.02 & 0.01 & 0.131 \\
\hline & $35+$ & -0.09 & 0.03 & $<0.001$ & -0.07 & 0.03 & 0.009 \\
\hline \multirow[t]{4}{*}{ Wife's at age marriage } & Up to 24 & 0.33 & 0.01 & $<0.001$ & 0.35 & 0.01 & $<0.001$ \\
\hline & $25-29$ & & & & & & \\
\hline & $30-34$ & -0.29 & 0.02 & $<0.001$ & -0.29 & 0.02 & $<0.001$ \\
\hline & $35+$ & -0.93 & 0.04 & $<0.001$ & -0.91 & 0.04 & $<0.001$ \\
\hline \multirow[t]{5}{*}{ Husband's education } & Primary & 0.20 & 0.01 & $<0.001$ & 0.21 & 0.01 & $<0.001$ \\
\hline & Secondary & & & & & & \\
\hline & College & -0.28 & 0.01 & $<0.001$ & -0.29 & 0.01 & $<0.001$ \\
\hline & Graduate & -0.41 & 0.02 & $<0.001$ & -0.42 & 0.02 & $<0.001$ \\
\hline & Missing & 0.33 & 0.05 & $<0.001$ & 0.31 & 0.05 & $<0.001$ \\
\hline \multirow[t]{5}{*}{ Wife's education } & Primary & 0.28 & 0.01 & $<0.001$ & 0.27 & 0.01 & $<0.001$ \\
\hline & Secondary & & & & & & \\
\hline & College & -0.31 & 0.01 & $<0.001$ & -0.31 & 0.01 & $<0.001$ \\
\hline & Graduate & -0.38 & 0.04 & $<0.001$ & -0.37 & 0.04 & $<0.001$ \\
\hline & Missing & 0.39 & 0.06 & $<0.001$ & 0.38 & 0.06 & $<0.001$ \\
\hline \multirow[t]{5}{*}{ Husband's income } & $\begin{array}{l}\text { Less than } \\
50 \mathrm{~K}\end{array}$ & 0.41 & 0.01 & $<0.001$ & 0.43 & 0.02 & $<0.001$ \\
\hline & $50-100 \mathrm{~K}$ & 0.09 & 0.01 & $<0.001$ & 0.09 & 0.01 & $<0.001$ \\
\hline & $100-150 \mathrm{~K}$ & & & & & & \\
\hline & $150-200 \mathrm{~K}$ & -0.01 & 0.02 & 0.488 & 0.01 & 0.02 & 0.833 \\
\hline & $200 \mathrm{~K}+$ & 0.05 & 0.02 & 0.056 & 0.08 & 0.02 & 0.002 \\
\hline \multirow[t]{5}{*}{ Wife's income } & $\begin{array}{l}\text { Less than } \\
25 \mathrm{~K}\end{array}$ & -0.47 & 0.02 & $<0.001$ & -0.45 & 0.02 & $<0.001$ \\
\hline & $25-50 \mathrm{~K}$ & -0.58 & 0.02 & $<0.001$ & -0.56 & 0.02 & $<0.001$ \\
\hline & $50-100 \mathrm{~K}$ & -0.41 & 0.02 & $<0.001$ & -0.41 & 0.02 & $<0.001$ \\
\hline & $100-150 \mathrm{~K}$ & & & & & & \\
\hline & $150 \mathrm{~K}+$ & 0.09 & 0.04 & 0.026 & 0.11 & 0.04 & 0.005 \\
\hline
\end{tabular}


Table 3 continued

\begin{tabular}{|c|c|c|c|c|c|c|c|}
\hline \multirow[t]{2}{*}{ Variable } & \multirow[t]{2}{*}{ Category } & \multicolumn{3}{|c|}{ Model 1: no fixed-effects } & \multicolumn{3}{|c|}{ Model 2: with fixed-effects } \\
\hline & & $B$ & SE $B$ & $p$ & $B$ & SE $B$ & $p$ \\
\hline \multirow{4}{*}{$\begin{array}{l}\text { Husband's family } \\
\text { structure }\end{array}$} & Intact family & & & & & & \\
\hline & $\begin{array}{l}\text { Parental } \\
\text { death }\end{array}$ & 0.03 & 0.02 & 0.239 & 0.03 & 0.02 & 0.278 \\
\hline & $\begin{array}{l}\text { Parental } \\
\text { divorce }\end{array}$ & 0.43 & 0.02 & $<0.001$ & 0.39 & 0.02 & $<0.001$ \\
\hline & Indeterminate & 0.18 & 0.01 & $<0.001$ & 0.17 & 0.01 & $<0.001$ \\
\hline \multirow[t]{4}{*}{ Wife's family structure } & Intact family & & & & & & \\
\hline & $\begin{array}{l}\text { Parental } \\
\text { death }\end{array}$ & 0.04 & 0.02 & 0.081 & 0.04 & 0.02 & 0.075 \\
\hline & $\begin{array}{l}\text { Parental } \\
\text { divorce }\end{array}$ & 0.59 & 0.01 & $<0.001$ & 0.55 & 0.01 & $<0.001$ \\
\hline & Indeterminate & 0.29 & 0.01 & $<0.001$ & 0.28 & 0.01 & $<0.001$ \\
\hline \multirow{2}{*}{$\begin{array}{l}\text { Husband's school } \\
\text { enrollment }\end{array}$} & No & & & & & & \\
\hline & Yes & -0.01 & 0.02 & 0.755 & -0.02 & 0.02 & 0.342 \\
\hline \multirow{2}{*}{$\begin{array}{l}\text { Wife's school } \\
\text { enrollment }\end{array}$} & No & & & & & & \\
\hline & Yes & 0.46 & 0.02 & $<0.001$ & 0.45 & 0.02 & $<0.001$ \\
\hline \multirow{10}{*}{$\begin{array}{c}\text { Parity and age of } \\
\text { youngest child }\end{array}$} & Childless & & & & & & \\
\hline & 1. 0 years & -1.58 & 0.04 & $<0.001$ & -1.57 & 0.04 & $<0.001$ \\
\hline & 1. $1-6$ years & -0.34 & 0.01 & $<0.001$ & -0.34 & 0.01 & $<0.001$ \\
\hline & 1. $7+$ years & 0.02 & 0.02 & 0.084 & 0.03 & 0.02 & 0.251 \\
\hline & 2. 0 years & -1.65 & 0.03 & $<0.001$ & -1.64 & 0.03 & $<0.001$ \\
\hline & 2. 1-6 years & -0.59 & 0.01 & $<0.001$ & -0.58 & 0.01 & $<0.001$ \\
\hline & 2. $7+$ years & -0.34 & 0.02 & $<0.001$ & -0.32 & 0.02 & $<0.001$ \\
\hline & $3+.0$ years & -2.03 & 0.06 & $<0.001$ & -2.01 & 0.06 & $<0.001$ \\
\hline & $\begin{array}{l}3+.1- \\
6 \text { years }\end{array}$ & -0.82 & 0.02 & $<0.001$ & -0.80 & 0.02 & $<0.001$ \\
\hline & $3+.7+$ years & -0.40 & 0.03 & $<0.001$ & -0.38 & 0.03 & $<0.001$ \\
\hline \multicolumn{2}{|l|}{ Population density } & 0.00003 & 0.00002 & 0.063 & -0.0007 & 0.0004 & 0.060 \\
\hline \multicolumn{2}{|c|}{ Alternative sex ratio linear } & $0.0988 * * *$ & 0.0081 & $<0.001$ & $0.0973 * * *$ & 0.0088 & $<0.001$ \\
\hline \multicolumn{2}{|c|}{ Alternative sex ratio squared } & $-0.0005 * * *$ & 0.00004 & $<0.001$ & $-0.0005 * * *$ & 0.0000 & $<0.001$ \\
\hline \multicolumn{2}{|c|}{ Proportion with higher education } & $0.0082 * * *$ & 0.0013 & $<0.001$ & $-0.0335 * * *$ & 0.0063 & $<0.001$ \\
\hline \multicolumn{2}{|c|}{ Mean income } & $0.0047 * * *$ & 0.0010 & $<0.001$ & 0.0044 & 0.0029 & 0.216 \\
\hline \multicolumn{2}{|l|}{ Unemployment rate } & $0.0395 * * *$ & 0.0049 & $<0.001$ & -0.0088 & 0.0072 & 0.342 \\
\hline$-2 \log$ likelihood & \multicolumn{3}{|c|}{495713.5} & \multicolumn{2}{|c|}{493891.5} & & \\
\hline
\end{tabular}

Note: In both of these models all community characteristics are included. Estimates for period effects and, for Model 2, the community fixed-effects are not shown in order to save space

$* p<5 \%$;* $p<1 \%$;*** $p<0.1 \%$ 


\section{References}

Allison, P. D. (1995). Survival analysis using the SAS system. Cary, NC: SAS Institute.

Amato, P. R. (1993). Children's adjustment to divorce-theories, hypotheses, and empirical support. Journal of Marriage and the Family, 55(1), 23-38.

Amato, P. R. (2000). The consequences of divorce for adults and children. Journal of Marriage and the Family, 62(4), 1269-1287.

Astone, N. M., Nathanson, C. A., Schoen, R., \& Kim, Y. J. (1999). Family demography, social theory, and investment in social capital. Population and Development Review, 25(1), 1-32.

Bracher, M., Santow, G., Morgan, S. P., \& Trussel, J. (1993). Marriage dissolution in Australia: Models and explanations. Population Studies, 47(3), 403-425.

Festinger, L. (1954). A theory of social comparison processes. Human Relations, 7(2), 117-140.

Goldstein, H. (2003). Multilevel statistical models (3rd ed.). London: Arnold.

Hedström, P. (2005). Dissecting the social. On the principles of analytical sociology. Cambridge: Cambridge University Press.

Hyman, H. H. (1960). Reflections on reference groups. The Public Opinion Quarterly, 24(3), 383-396.

Inglehart, R. (1990). Culture shift in advanced industrialized societies. Princeton: Princeton University Press.

Inglehart, R. (1997). Modernization and post-modernization. Princeton: Princeton University Press.

Jahoda, M., Lazarsfeld, P. M., \& Zeisel, H. (1933). Die Arbeitslosen von Marienthal: Ein soziographischer Versuch ueber die Wirkungen langdauernder Arbeitslosigkeit, mit einem Anhang zur Geschichte der Soziographie. Frankfurt am Main: Suhrkamp.

Jalovaara, M. (2003). The joint effects of marriage partners' socioeconomic positions on the risk of divorce. Demography, 40(1), 67-81.

Kalmijn, M., \& Flap, H. (2001). Assortative meeting and mating: Unintended consequences of organized settings for partner choices. Social Forces, 79(4), 1289-1312.

Kalmijn, M., \& Poortman, A.-R. (2006). His or her divorce? The gendered nature of divorce and its determinants. European Sociological Review, 22(2), 201-214.

Kalmijn, M., \& Uunk, W. (2007). Regional value differences in Europe and the social consequences of divorce: A test of the stigmatization hypothesis. Social Science Research, 36(2), 447-468.

Kravdal, Ø. (2002). The impact of individual and aggregate unemployment on fertility in Norway. Demographic Research, 6(10), 264-294.

Kravdal, Ø. (2007). A fixed-effects multilevel analysis of how community family structure affects individual mortality in Norway. Demography, 44(3), 519-537.

Kravdal, Ø. (2008). Does income inequality really influence individual mortality? Results from a 'fixedeffects analysis' where constant unobserved municipality characteristics are controlled. Demographic Research, 18(7), 205-232.

Kulu, H., Vikat, A., \& Andersson, G. (2007). Settlement size and fertility in the Nordic countries. Population Studies, 61(3), 265-285.

Lampard, R. (2007). Couples' places of meeting in late 20th century Britain: Class, continuity and change. European Sociological Review, 23(3), 357-371.

Lesthaeghe, R., \& Neels, K. (2002). From the first to the second demographic transition: An interpretation of the spatial continuity of demographic innovation in France, Belgium and Switzerland. European Journal of Population, 18(4), 325-360.

Lichter, D. T., LeClere, F. B., \& McLaughlin, D. (1991). Local marriage markets and the marital behaviour of black and white men. American Journal of Sociology, 96(4), 843-867.

Listhaug, O. (1998). Norske verdier og holdninger 1982-1996: Sentrale verdier endrer seg sakte. Samfunnsspeilet, 12(1), 2-9.

Lloyd, K. M., \& South, S. J. (1996). Contextual influences on young men's transition to first marriage. Social Forces, 74(3), 1097-1119.

Luttmer, E. F. P. (2005). Neighbors as negatives: Relative earnings and well-being. Quarterly Journal of Economics, 120(3), 963-1002.

Lyngstad, T. H. (2004). The impact of parents' and spouses' education on divorce rates in Norway. Demographic Research, 10(5), 122-142.

Lyngstad, T. H. (2006). Why do couples with highly educated parents have higher divorce risk? European Sociological Review, 22(1), 49-60. 
Lyngstad, T. H., \& Noack, T. (2005). Vil de velge bort familien? Analyser av unge nordmenns ekteskapsog fruktbarhetsintensjoner. Tidsskrift for velferdsforskning, 8(3), 120-134.

Lyngstad, T. H., \& Jalovaara, M. (2010). A review of the antecedents of union dissolution. Demographic Research, 23(10), 257-292.

McKinnish, T. G. (2007). Sexually integrated workplaces and divorce-Another form of on-the-job search. Journal of Human Resources, 42(2), 331-352.

Pickett, K. E., \& Pearl, M. (2001). Multilevel analyses of neighbourhood socioeconomic context and health outcomes: A critical review. Journal of Epidemiology and Community Health, 55(2), $111-122$.

Rindfuss, R. R., Guilkey, D., Morgan, S. P., Kravdal, Ø., \& Guzzo, K. B. (2007). Child care availability and first-birth timing in Norway. Demography, 44(2), 345-372.

Røed, K., \& Raaum, O. (2003). Administrative registers-Unexplored reservoirs of scientific knowledge? Economic Journal, 113(488), F258-F281.

Sampson, R. J., Raudenbush, S. W., \& Earls, F. (1997). Neighbourhoods and violent crime: A multilevel study of collective efficacy. Science, 277(5328), 918-924.

Shelton, B. A. (1987). Variations in divorce rates by community size-A test of the social integration explanation. Journal of Marriage and the Family, 49(4), 827-832.

South, S. J. (2001). The geographic context of divorce: Do neighborhoods matter? Journal of Marriage and the Family, 63(3), 755-766.

South, S. J., \& Crowder, K. D. (1999). Neighborhood effects on family formation: Concentrated poverty and beyond. American Sociological Review, 64(1), 113-132.

South, S. J., \& Lloyd, K. M. (1995). Spousal alternatives and marital dissolution. American Sociological Review, 60(1), 21-35.

South, S. J., Trent, K., \& Shen, Y. (2001). Changing partners: Toward a macrostructural-opportunity theory of marital dissolution. Journal of Marriage and the Family, 63(3), 743-754.

Statistics Norway. (2010). Available from http://statbank.ssb.no/statistikkbanken/Default_FR.asp?PX Sid $=0 \& n v l=$ true $\&$ PLanguage $=0 \&$ tilside $=$ selectvarval $/$ define. asp $\&$ Tabellid $=06854$.

Stutzer, A. (2004). The role of income aspirations in individual happiness. Journal of Economic Behaviour and Organization, 54(1), 89-109.

Sucoff, C. A., \& Upchurch, D. (1998). Neighborhood context and the risk of childbearing among metropolitan-area Black residents. American Sociological Review, 63(3), 571-585.

Svarer, M. (2007). Working late-Do workplace sex ratios affect partnership formation and dissolution? Journal of Human Resources, 42(3), 583-595.

Udry, J. R. (1983). The marital happiness/disruption level by level of marital alternatives. Journal of Marriage and the Family, 45(1), 221-222.

White, L. K. (1990). Determinants of divorce-A review of research in the $80 \mathrm{~s}$. Journal of Marriage and the Family, 52(4), 904-912. 